\title{
Hedonic Consequences of Social Comparison: A Contrast of Happy and Unhappy People
}

\author{
Sonja Lyubomirsky \\ University of California, Riverside
}

\author{
Lee Ross \\ Stanford University
}

\begin{abstract}
Two studies tested the hypothesis that self-rated unhappy individuals would be more sensitive to social comparison information than would happy ones. Study 1 showed that whereas unhappy students' affect and self-assessments were heavily affected by a peer who solved anagrams either faster or slower, happy students' responses were affected by the presence of a slower peer only. These between-group differences proved to be largely independent of 2 factors associated with happiness, i.e., self-esteem and optimism. Study 2 showed that whereas the unhappy group's responses to feedback about their own teaching performance were heavily influenced by a peer who performed even better or even worse, happy students' responses again were moderated only by information about inferior peer performance. Implications for our appreciation of the link between cognitive processes and "hedonic" consequences are discussed.
\end{abstract}

Self-perceptions and self-evaluations depend not only on the absolute nature of one's accomplishment and performance but also on the way one measures up to relevant peers (Festinger, 1954; Suls, 1977; Wills, 1981, 1991). Opportunities for such social comparison are ubiquitous, as everyday social interactions and the media inundate us with information about other people's accomplishments, actions, and lifestyles. Furthermore, the comparison process itself often seems relatively automatic. Most find it next to impossible to hear about others' successes and failures, or good and bad fortune, without reflecting on their own accomplishments and status. People learn early in life that success often is a matter of relative rather than absolute performance and, consequently, strive to learn how they stand relative to "relevant others." Indeed, such social comparison processes often may be highly adaptive. As Festinger (1954) suggested, successful social functioning requires people to evaluate the merits of their views and abilities, and in the absence of objective information, such evaluation necessarily depends on social comparison.

Because Festinger and his colleagues so emphasized evalua-

Sonja Lyubomirsky, Department of Psychology, University of California, Riverside; Lee Ross, Department of Psychology, Stanford University.

This research was supported by a National Science Foundation graduate fellowship, a National Institute of Mental Health (NIMH) national research service award, and an NIMH research grant. We are grateful to Robert Dickert and Gilbert Lo for their invaluable assistance in conducting Studies 1 and 2, respectively.

Correspondence concerning this article should be addressed to Sonja Lyubomirsky, Department of Psychology, University of California, Riverside, California 92521. Electronic mail may be sent via the Internet to sonja@citrus.ucr.edu. tive needs and functions, the early literature on social comparison focused primarily on the selection of comparison sources and the resulting "pressures to uniformity" and motivation to improve performance. More recently, however, researchers increasingly have shifted their focus from the dynamics of the comparison process itself to the hedonic consequences of such comparison. Much of this work has proceeded from the simple assumption that upward comparisons generally are threatening to well-being and self-esteem, whereas downward comparisons are self-enhancing or reassuring. Many laboratory and field studies (e.g., Morse \& Gergen, 1970; Wheeler \& Miyake, 1992) have supported this proposition, showing that greater increases or smaller decreases in participants' subjective well-being (e.g., elevated mood, enhanced self-esteem) follow downward comparison (e.g., Hakmiller, 1966) and greater decreases or smaller increases in subjective well-being follow upward comparison (e.g., Wood, Taylor, \& Lichtman, 1985).

Empirical and anecdotal evidence, however, suggests that the affective consequences of a social comparison often may depend less on its direction than on the context and manner of its use (e.g., Brickman \& Bulman, 1977; Buunk, Collins, Taylor, VanYperen, \& Dakof, 1990; Taylor \& Lobel, 1989; Tesser, 1988). Thus, cancer patients may derive solace from comparisons with real or hypothetical peers whose symptoms or circumstances are even more dire than their own (Wood et al., 1985), but they may also report feeling inspired, optimistic, and hopeful from "upward" contacts with good copers and long-term survivors (Buunk et al., 1990; Taylor, Aspinwall, Giuliano, Dakof, \& Reardon, 1993). More generally, a peer's success can be a source of either envy and self-doubt or of inspiration and motivation, and a peer's misfortune may make one feel either fortunate to have escaped such a fate or afraid that a similar fate awaits in the future. 
The nature of one's relationship with a social comparison target, and the nature of the evaluative dimension, may similarly play a rolc. A peer's success or good fortune obviously can produce depression, jealousy, and lowered self-esteem, but it also can be a source of inspiration, pride, and optimism, provided that one identifies with that "superior" " peer (Tesser, 1988; Wheeler, 1966; Wills, 1981; for empirical evidence, see Major, Testa, \& Bylsma, 1991; Tesser, Millar, \& Moore, 1988). Conversely, although a peer's failure or bad fortune can boost one's sense of relative worth or status, it also can be depressing or even threatening if one feels connected with or similar to that peer, especially if the relevant evaluative dimension is one on which one's own status is likely to deteriorate. Again, however, such effects are variable and are likely to depend on highly subjective factors that are similarly variable and circumstantial. For example, cancer patients who believed that they had relatively little control over the course of their disease experienced much more negative affect after exposure to very sick patients than did patients who believed that they had relatively more control (Buunk et al., 1990).

\section{Individual Differences}

Laboratory and anecdotal evidence of the flexibility of social comparison, and the resulting variability of its hedonic consequences, naturally prompts us to consider the phenomenon of individual differences. Everyone can identify individuals who seemed to feel deflated rather than delighted when their roommate graduated summa cum laude or found a new love, and who felt relieved rather than disappointed or sympathetic when their colleague was rejected in seeking some new honor, promotion, or relationship. Moreover, whereas some people's mond and more enduring sense of well-being seemingly depend heavily on social comparison, other people's happiness or unhappiness seems to depend little on such information. Our present research essentially sought to reverse the emphasis of such anecdotal observation. We sought to show that characteristically happy and unhappy people differ in the extent and manner of their responsiveness to social comparison information. Specifically, we hypothesized that happy individuals are more inclined than unhappy ones to "use" such information sparingly, and to use it selectively to protect their well-being and self-esteem.

Our current research represents another step in a more general research undertaking on the links among affective temperament, motivation, cognitive processes, and hedonic consequences. In one recently completed set of studies (Lyubomirsky \& Ross, 1997 ), we sought to show the mediating role that temperament may play in determining the cognitive and motivational consequences of choice or restriction of alternatives. Our findings suggested that self-rated happy and unhappy individuals responded differently - and in a manner supportive of their affective temperaments - - in reducing dissonance in the aftermath of decision making. Whether in choosing fancy desserts or selecting among prospective colleges, happy people tended to be satisfied with all of their options-even those they did not ultimately choose or receive--and to reduce dissonance in the face of real ego threat (e.g., by devaluing colleges that rejected them). By contrast, unhappy people generally reduced dissonance by deciding that what they chose or received was medio- cre but that what they were denied was even worse. In earlier pilot research (Lyubomirsky \& Ross, 1990), we explored group differences in recollection and in assessment changes over time with respect to a wide range of recent positive versus negative life events. Happy and unhappy respondents, we found, differed neither in the frequency of occurrence nor in the objective magnitude of the positive and negative events they faced. But happy participants resolved ambiguity about both types of events more favorably and adaptively, showed more rapid declines in negative affect, and were more likely to see humor and didactic value in adversity.

Although we know of no research that has specifically examined social comparison processes among happy versus unhappy individuals, there is some suggestive evidence (albeit from studies using paradigms very different from our present ones) that individual differences related to enduring levels of happiness may be associated with differences in the way such processes are used. Low self-esteem in particular seems to be associated with the tendency for people to compare themselves with less fortunate others (e.g., Cialdini \& Richardson, 1980; DeVellis et al., 1990; Taylor, Wood, \& Lichtman, 1983; Wood, GiordanoBeech, Taylor, Michela, \& Gaus, 1994; see Wills, 1981, for a review), to derogate others (Cialdini \& Richardson, 1980; Crocker, Thompson, McGraw, \& Ingerman, 1987), and to suffer negative consequences from social comparison in general and upward comparison, in particular (e.g., Buunk et al., 1990; Gibbons \& Gerrard, 1989; Wheeler \& Miyake, 1992). Low self-esteem seems also to increase people's reliance on social comparisons for self-evaluation (e.g., Brickman \& Berman, 1971; Wayment \& Taylor, 1995; see also Morse \& Gergen, 1970). Clinically inspired studies investigating the consequences of mild to moderate depression are similarly suggestive; that is, depression appears to be correlated with reliance on social comparison information, especially unfavorable information (e.g., Gibbons, 1986; Swallow \& Kuiper, 1988, 1990, 1992) and negative responses to such information (c.g., Ahrens, 1991; Weary, Elbin, \& Hill, 1987).

\section{The Current Studies}

Our working hypothesis in the present research was that happy individuals would be less sensitive to unsolicited social comparison information in general, and less vulnerable to unfavorable social comparison information in particular, than unhappy individuals. In Study 1 we allowed participants to solve anagrams at whatever rate they were capable of, but we manipulated the ostensible performance of a school peer so that participants experienced relative success (i.e., their peer performed worse than they) or relative failure (i.e., their peer performed better than they). In Study 2 we manipulated participants' apparent success or failure in a teaching task (by means of "expert" feedback) and examined the extent to which relative social comparison information (i.e., information suggesting that a peer had done even better or even worse) would moderate the effects of their own absolute success or failure.

Beyond the featured comparison of happy and unhappy participants, our two studies shared a number of common features. First, to minimizc possible experimental demand characteristics and suspicion on the part of participants, and to better simulate 
typical real-world social comparison contexts, we provided social comparison information indirectly in both studies. That is, the experimenter never explicitly offered any comparison of performances, although through careful staging, such information was made highly salient to the participants. Second, in both studies, the relevant task and evaluation dimension was one likely to be at least moderately important to the participants, yet it was a dimension about which they were unlikely to have objective standards for evaluating their performance. Finally, in both studies, participants enjoyed wide latitude in "managing" the relevant social comparison process. They were free to minimize or maximize the self-relevance, importance, and controllability of the dimension under evaluation; they were free to compete with, identify with, or simply ignore their more successful or less successful peer; and they were free to attribute their own performance or that of their peers to whatever factors (stable vs. unstable, global vs. specific, internal vs. external, etc.) they wished.

\section{Study 1}

Method

\section{Overview}

In the context of a purported study of cognitive performance, selfrated happy and unhappy female undergraduates solved anagram puzzles while a supposed peer (who was actually an experimental confederate) ostensibly completed the same puzzles much faster or much slower than the participants. Participants rated themselves with respect to their current mood, confidence, and anagram-solving ability both before and after the completion of their task.

\section{Participants}

Fifty female introductory psychology students at Stanford University received course credit for their participation in this study. Participants were selected on the basis of their responses to four Likert-type ratings of their own happiness presented in the context of a mass-administered omnibus questionnaire. The first item asked them to characterize themselves using absolute ratings $(1=a$ very unhappy person; $7=a$ very happy person). The second item asked them to characterize themselves relative to Stanford peers $(1=$ much less happy; $7=$ much more happy $)$. The third and fourth items, respectively, characterized happy people ("Some people are generally very happy; they enjoy life regardless of what is going on, getting the most out of everything") and unhappy people ("Some people are generally not very happy; although they are not depressed, they never seem as happy as they might be"), and each item asked participants to what extent each characterization described them $(1=$ not at all; $7=a$ great deal $)$. Responses to the four items, which showed high internal consistency (Cronbach's $\alpha=.94$ ), were combined and averaged to provide a single composite score, ranging from 1.0 to 7.0 , with a median of 5.5 on the 7-point scale.'

A sample of 25 happy and 25 unhappy participants, that is, those whose composite scores were respectively either in the top or bottom quarter of the distribution (but excluding participants who scored 7 and above on the short form of the Beck Depression Inventory [BDI; Beck \& Beck, 1972; see Beck \& Beamesderfer, 1974]), were recruited for the study by telephone. The correlation between participants' BDI scores and their scores on our happiness composite, we should note, was relatively modest $(r=-.38$ ). The happy participants' group mean on the relevant happiness scale was $6.55(S D=0.66)$, whereas the group mean for the unhappy participants was $3.44(S D=1.17) .^{2}$ We should note that the omnibus questionnaire used in selecting these participants included two scales, Rosenberg's (1965) Self-Esteem Scale $(\alpha=.90)$ and Scheier and Carver's (1985) Life Orientation Test (an optimism scale; $\alpha=.87$ ), measuring constructs conceptually and empirically linked to happiness. The inclusion of these scales, although not specifically intended for this purpose, later allowed us to pursue issues of discriminant validity.

\section{Procedure and Materials}

In each experimental session, two individuals, a female participant and a female confederate pretending to be another participant, completed the relevant questionnaires and experimental tasks together. The experimenter, a young male (who was not informed of participants' happiness status), explained that participants were being paired simply to "save time."

The experiment was introduced as a study of "cognitive performance," one in which we "hoped to learn how personality and various situational variables affect performance on a problem-solving task." Accordingly, participants were told, they would be asked to solve a series of anagrams during the experimental session. To bolster this purported rationale for the study, we embedded a number of filler items, including questions about how often participants solved puzzles, how much they enjoyed them, and how important it is for them to be good at them, as

\footnotetext{
${ }^{1}$ In previous research in our laboratory, this composite measure has demonstrated high internal consistency (Cronbach's alphas range from .85 to .95 in seven different studies), high test-retest stability (Pearson's product-moment correlation $=.90$ for 4 weeks and .71 for 3 months). It further has been shown to correlate highly with peer ratings of happiness $(r=.65)$ solicited in a telephone follow-up; with Scheier and Carver's (1985) Life Orientation Test ( $r$ s range from .47 to .62 in four studies); with Rosenberg's (1965) Self-Esteem Scale ( $r$ s range from .53 to .58 in four studies); with the Beck Depression Inventory (Beck \& Beck, 1972 ; $r$ s range from -.49 to -.65 in four studies); with extroversion $(r=.36)$ and neuroticism $(r=-.50)$, as assessed by the Eysenck Personality Questionnaire (Eysenck \& Eysenck, 1975); and with positive emotionality $(r=.48)$ and negative emotionality $(r=-.39)$, as assessed by Tellegen's (1985) Differential Personality Questionnaire. Furthermore, our composite measure has shown strong relationships with other widely used scales of subjective well-being, such as Bradburn's (1969) Affect-Balance Scale ( $r$ s range from .49 to .64 in three studies) and his Global Happiness item ( $r$ s range from .57 to .69 in three studies), Andrews and Withey's (1976) Terrible-Delighted Scale ( $r$ s range from .59 to .71 in three studies), and Diener, Emmons, Larsen, and Griffin's (1985) Satisfaction With Life Scale ( $r$ s range from .61 to .69 in three studies). No significant correlations have been found between our composite happiness measure and college grade point average, math and verbal ability, age, gender, and education. (For further information on the characteristics and correlates of this composite measure, see Lyubomirsky \& Lepper, 1997.)

${ }^{2}$ Given the absolute values of these means, one could argue that the unhappy group might better be labeled as "not happy" or even "average." We were guided, however, by research showing that on measures of current or long-term affective state, and indeed on most measures of well-being, life satisfaction, or self-esteem, people tend to show overall means that are on the high or above average end of the scale (Bradburn, 1969; A. Campbell, Converse, \& Rodgers, 1976; Rosenberg, 1965; Watson, Clark, \& Tellegen, 1988). Accordingly, the self-ratings of our current unhappy participants, which were just slightly below the midpoint of 4.0 on the relevant scale, meant that they were unhappy relative not only to our self-labeled happy participants but also to their peers in the population as a whole.
} 
well as their SAT scores, in the various questionnaires administered throughout the study.

Before undertaking the primary experimental task, participants completed a preliminary questionnaire assessing their premanipulation, or baseline, mood on 9-point Likert-lype scales asking how good, happy, and depressed they currently were feeling. These scales were combined to provide a single mood index on which more positive scores reflected more positive moods $(\alpha=.88)$. We used the individual Likert-type scales, rather than longer mood inventories, to avoid alerting participants to our specific topic of concern and our hypotheses. ${ }^{3}$ Participants also provided baseline measures assessing how good they initially thought they were at solving anagrams $(1=$ very poor; $7=$ excellent $)$ and how they thought they would rank relative to their peers (i.e., how many of a randomly selected group of 100 Stanford students would be better than they were at solving anagrams).

Anagram-solving task and social comparison manipulation. After the participants had completed the preliminary questionnaire, the experimenter gave them instructions for the 20 -min anagram-solving task. He began by handing each of them a "sample" puzzle card containing three anagrams - that is, Y-O-W-N-S (SNOWY), N-O-T-I-X (TOXIN), and A-S-S-I-B (BASIS ) - and indicating that such cards would be used throughout the solution task. He further explained that upon unscrambling any two of the three anagrams on a given card, participants were to write their solutions and the card number on their answer sheet, then hand the card back to the experimenter and receive a new card containing new anagrams. Participants were also given a notebook to use as scratch paper (one page per card). At that point, the experimenter instructed them to begin solving anagrams and handing in their cards. What the participants did not know, of course, was that their coparticipant was an experimental confederate who had been instructed to monitor their partner's pace and solve either approximately $50 \%$ more or $50 \%$ fewer anagrams than she did-a task they accomplished very successfully. The back-and-forth handing of the anagram cards as the participant and confederate worked side by side throughout the 20 -min period, along with the consecutive numbering of the cards and the turning of notebook pages, served to make it highly salient to participants that their peer's performance was either highly superior or highly inferior to their own.

While the participant and the confederate were performing the anagram-solving task, the experimenter surreptitiously rated the participant's apparent level of anxiety and dysphoria, using 7-point Likerttype scales ( $1=$ not at all; $7=$ a great deal $)$ after $5 \mathrm{~min}$ and then again after 15 min. These two pairs of ratings were subsequently combined to provide a single index of apparent negative mood $(\alpha=.89)$.

Postperformance questionnaires. Immediately following the 20-min anagram task, the participant and the confederate were put in separate rooms, and the participant was asked by the experimenter to complete a second set of self-assessments of mood and anagram-solving abilities. Participants were required to rate how good, sad, and happy they currently were feeling, using 9-point Likert-type scales $(\alpha=.92)$. They further were asked to use similar 9-point Likert-type scales to rate, retrospectively, how frustrated, happy, down, and anxious they recalled having felt earlier $(\alpha=.81)$, while actually solving the anagrams. To assess changes in participants' perceptions of their own ability in light of their performance and the apparently superior or inferior performance of their peer, we asked participants to again rate how good they thought they were at solving anagrams $(1=$ very poor; $7=$ excellent $)$ and to estimate their probable ranking in a randomly selected group of 100 Stanford students. Participants were also asked to rate their own justcompleted task performance and that of the confederate using simple 7 point scales $(1=$ very poor; $7=$ excellent $)$. To further bolster our purported rationale for the study, and to deflect participants' attention from our primary concerns, we also asked participants at various points in the questionnaire to respond to a number of filler items about the anagram-solving task (i.e., what strategies they used) and about problem solving in general.

Finally, when all dependent variable measures had been collected, participants completed a debriefing questionnaire in which they first were given an opportunity to describe their feelings, concerns, and suspicions regarding the study and then were asked to rate how much they liked the experiment overall $(1=$ not at all $; 7=a$ great deal $)$. In order to check on whether our procedures were successful in minimizing suspicion and possible experimental demand characteristics, participants were then asked, both on a debriefing questionnaire and during oral debriefing, to share their hunches about the hypotheses of the study and to report any other suspicions about the study. As it turned out, none of the participants guessed the purpose of the study or discerned the link between this study and the ratings of happiness they had completed several weeks earlier. The entire session lasted approximately $1 \mathrm{hr}$.

\section{Results}

\section{Premanipulation Measures}

Measures completed prior to the anagram-solving task suggested no between-group differences in ability or experience. That is, happy and unhappy participants did not differ significantly in their SAT scores, in their initial self-ratings of ability at solving anagrams, in their reports of how often they solved anagrams, in how much they enjoyed solving them, or in how important it was for them to be good at solving them (all ts $<$ 1). The only baseline difference involved mood. That is, happy participants began the study reporting significantly more positive overall moods $(M=6.72, S D=1.09)$ than unhappy participants $(M=5.72, S D=1.07), t(47)=3.27, p<.002$, a finding consistent not only with intuition but with other findings from our laboratory (Lyubomirsky \& Ross, 1997).

\section{Manipulation Check}

Overall, participants solved a mean of 17.8 anagrams ( $S D=$ 8.23 ) during the allotted 20 -min test period. Analyses revealed no significant performance differences between happy and unhappy participants overall $(t<1)$ or in either the faster peer or the slower peer condition (both $t s<1$ ). Nor, incidentally, was any main effect found for the effect of peer performance on the participants' own performance, $t(45)=0.55, n s$. As instructed, the confederate, depending on experimental condition, "solved" either considerably more anagrams $(M=26.6, S D=9.61)$ or considerably fewer anagrams $(M=12.8, S D=5.90)$ than the subject. The participants, moreover, showed themselves to be well aware of these performance differences. Those in the faster peer condition rated their peer as significantly better at solving anagrams $(M=5.57, S D=0.89)$ than did those in the slower peer condition $(M=3.86, S D=0.99), F(1,44)=40.08, p$ $<.0001$.

\section{Strategies for Primary Statistical Analyses}

We hypothesized that happy participants' moods and selfevaluations would be relatively uninfluenced by the performance

${ }^{3}$ Similar Likert-type scales, we should note, have been used effectively to measure mood in a number of previous studies (e.g., Aspinwall \& Taylor, 1993; Pittman et al., 1990; Wenzlaff, Wegner, \& Klein, $1991)$. 
of their peer, especially in cases where their peer's performance was superior to their own. Unhappy participants' moods and self-evaluations, by contrast, were expected to depend heavily on the quality of their peer's performance, regardless of whether their peer's performance was inferior or superior to their own. These hypotheses ultimately were tested both through planned pairwise comparisons of the failure and success conditions within the two groups (Rosenthal \& Rosnow, 1985; see also Rosnow \& Rosenthal, 1989) and through calculation of interaction effects between group (happy vs. unhappy) and condition (slower vs. faster peer). Simple change scores reflecting differences between premanipulation and postmanipulation ratings provided the primary dependent variables for both types of analyses. ${ }^{4}$ However, to test whether between-group differences obtained in this study were moderated by differences in transient mood, rather than the longer-term and presumably more stable self-assessments of general happiness, we also performed analyses using the participants' premanipulation mood as the covariate. Rather than taxing our readers unnecessarily, we merely note here that all such analyses relevant to our primary hypotheses yielded results very similar to those obtained when mood was not treated as a variable. That is, all significant main effects of group (happy vs. unhappy) and condition (slower vs. faster peer), and significant interactions between these variables, remained significant, and all nonsignificant main effects and interactions remained nonsignificant.

\section{Changes in Self-Assessments of Ability}

When they had found themselves outperforming a peer, both unhappy and happy participants offered ratings of their own ability that gave considerable weight to the relevant social comparison information. That is, both groups rated their ability at the anagram task more positively after working alongside a slower peer than they had rated it prior to undertaking the task (see Figure 1). The relevant change scores, based on 7-point rating scales, were statistically significant both for unhappy participants $(\triangle=+1.15$, $S D=0.99 ; t(13)=4.21, p<.002$ ) and for happy participants $(\bar{\Delta}=+1.55, S D=1.51 ; t(11)=3.40, p<.007)$, with no hint of a between-group difference $(t<1)$.

By contrast, when faced with a peer who clearly had outperformed them, the two groups, as hypothesized, reacted quite differently (see Figure 1). That is, whereas unhappy participants somewhat lowered their self-assessments of ability in the face of such unfavorable social comparison information $(\bar{\Delta}=$ $-0.42, S D=0.79 ; t(12)=1.82, p<.10)$, happy participants again showed elevated self-assessments $(\Delta=+0.79, S D=$ $1.25 ; t(14)=2.35, p<.04)$. This difference in change scores for unhappy versus happy participants was statistically significant, $t(22)=2.97, p<.009$. Conversely, considering each group separately, we found a significant effect of the relevant social comparison information for the unhappy participants, $t(22)=4.40, p<.0002$, but not for the happy participants, $t(19)=1.35, n s$. This pattern of means for change scores resulted in a significant main effect for group (unhappy vs. happy), $F(1,46)=5.87, p<.02$, as well as for peer performance (faster vs. slower peer), $F(1,46)=12.55, p<.001$. However, the relevant interaction effect failed to reach conventional levels of statistical significance $F(1,46)=1.52, n s .^{5}$
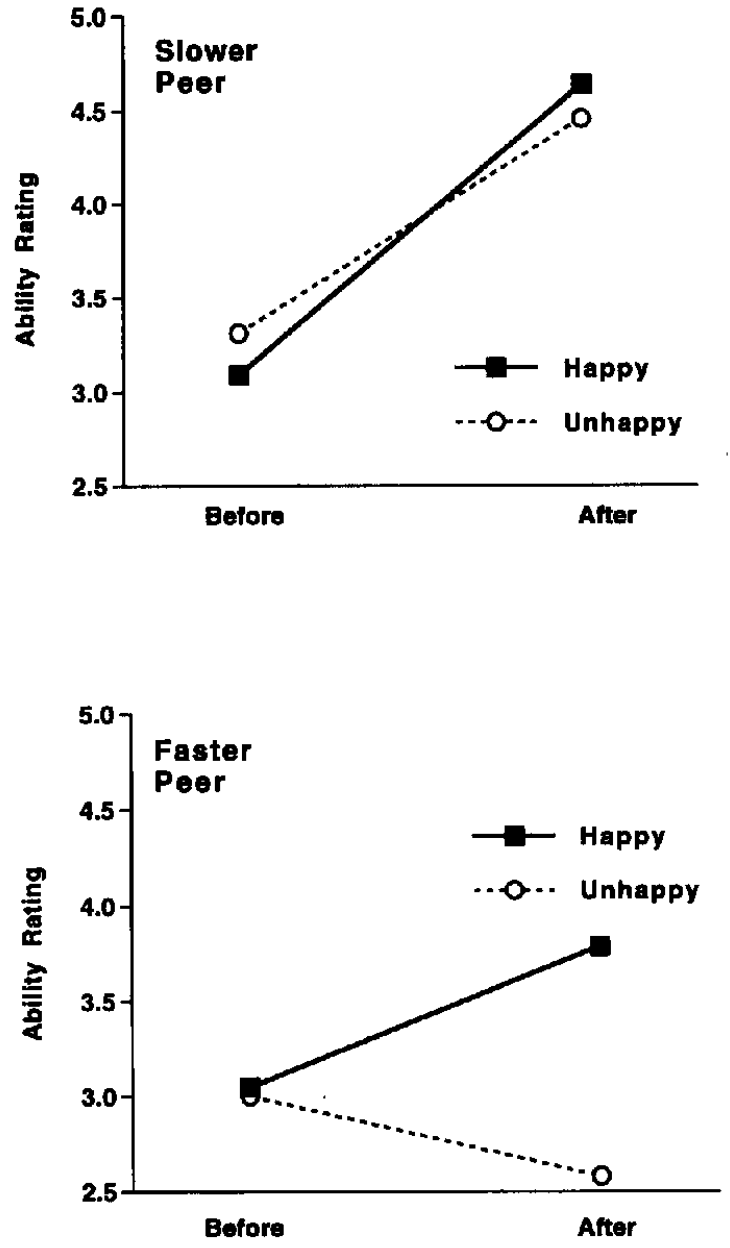

Figure 1 . Assessments of ability before and after working alongside a slower versus faster peer (Study 1).

\section{Changes in Self-Assessments of Mood}

Examination of changes in participants' self-reported mood produced a similar pattern of results. That is, unhappy and happy

\footnotetext{
${ }^{4}$ Other types of statistical analyses, principally analyses of covariance and repeated measures analyses, were also performed and yielded results virtually identical to those obtained in the analyses reported in this article; accordingly, in the interest of clarity and brevity, these results are not discussed further.

'Analyses of changes in participants' estimates of their probable ranking on anagram-solving performance in a randomly selected group of 100 students (i.e., "How many people would be worse than you?"') yielded similar, albeit weaker, results. For conditions in which participants outperformed a peer, this rating showed a significant increase both for unhappy participants $(\bar{\Delta}=+10.77 ; t(13)=-2.78, p<.02)$ and happy ones $(\bar{\Delta}=+17.27 ; t(11)=-3.27, p<.009)$. By contrast, when outperformed by a peer, unhappy participants significantly lowered their self-ratings ( $\bar{\Delta}=-8.75 ; t(12)=2.59, p<.03$ ), whereas happy participants showed a small but insignificant increase in their selfratings $(\bar{\Delta}=+2.71 ; t(14)=0.76, n s)$. Once again, however, the interaction effect reflecting this pattern of means for change scores failed to reach conventional significance levels.
} 
participants alike showed a positive change in mood after outperforming a slower peer $(\bar{\Delta}=+0.68, S D=0.58 ; t(12)=4.19$, $p<.002$, for unhappy participants; $\bar{\Delta}=+0.44, S D=0.66$; $t(9)=2.11, p<.06$, for happy participants ). However, only unhappy participants showed a negative change in $\operatorname{mood}(\bar{\Delta}=$ $-0.48, S D=0.56 ; t(11)=2.96, p<.02$ ) after having been outperformed by a faster peer; happy participants, in fact, showed a slight, though nonsignificant, positive change in mood ( $\bar{\Delta}=+0.15, S D=0.83$ ) despite the unfavorable social comparison provided by their peer's performance. Statistical analyses confirmed that change scores for the two groups did not differ significantly in the slower peer condition, $t(18)=-0.90, n s$, but did differ significantly in the faster peer condition, where the social comparison information was seemingly negative, $t(21)=$ $2.21, p<.04$. Conversely, when we consider each group separately, again there is a highly significant effect of the social comparison information provided by peer performance for the unhappy participants, $t(22)=5.06, p<.0001$, but not for the happy participants, $t(20)=0.94, n s$. Moreover, in contrast to the case for ability assessments, the relevant Group $\times$ Peer Performance interaction effect for mood assessments was statistically significant, $F(1,44)=4.87, p<.04$.

\section{Other Measures}

The suggestion that the subjective experiences of the happy and unhappy participants had been very different during the anagram-solving task was confirmed both by the participants" retrospective reports and by the experimenter's contemporaneous (blind) ratings. Thus, whereas unhappy participants retrospectively reported having felt significantly less positive moods during the task in the failure condition $(M=4.68, S D=0.78)$ than in the success condition $(M=6.31, S D=0.78), t(22)=$ $5.23, p<.0001$, happy participants recalled relatively similar positive moods in both conditions $(M=5.80, S D=0.98$, and $M=6.21, S D=1.18$, respectively ), $t(19)=0.93, n s$. This pattern of results yielded a statistically significant Group (happy vs. unhappy) $\times$ Peer Performance (slower vs. faster peer) interaction, $F(1,46)=5.23, p<.03$. Similarly, unhappy participants' moods had appeared significantly more negative to the experimenter in sessions in which they faced a faster peer $(M$ $=4.21, S D=0.83)$ than in sessions in which they faced a slower one $(M=3.44, S D=0.87), t(22)=2.22, p<.04$. Happy participants, by contrast, had manifested similar moods to the experimenter in both conditions $(M=3.66, S D=0.87$, and $M=3.43, S D=0.70$, respectively $, t(22)=0.73, n s$. In the case of experimenter assessments, however, the relevant Group $\times$ Peer Performance interaction failed to reach statistical significance, $F(1,45)=1.34, n s$.

It is interesting to note that the presence of a faster versus slower peer influenced not only the participants' moods and self-assessments of ability but also their overall reaction to the experiment. Whereas unhappy participants liked the experiment much more when they outperformed their peer $(M=4.96)$ than vice versa $(M=3.33), t(14)=2.86, p<.04$, happy participants liked the experiment about equally well in the two conditions ( $M=4.82$ and 4.43 , respectively), $t(22)=0.86, n s$. The resulting Group $\times$ Peer Performance interaction, however, was only marginally significant, $F(1,46)=2.92, p<.10$.

\section{Self-Esteem and Optimism as Possible Moderator Variables}

Readers might question whether the effects reported thus far really reflect the role of happiness rather than self-esteem, optimism, self-efficacy, or currently popular concepts that intuition and previous findings alike suggest should be correlated with happiness. ${ }^{6}$ Because the first two personality characteristics on this list were the object of measures included in our preexperimental test battery, we are fortunately in a position to begin to address this question.

With respect to self-esteem (as measured by Rosenberg's, 1965 , Self-Esteem Scale), the results of our analyses were simple and conclusive. When self-esteem was introduced as a covariate, we found that although it was indeed highly correlated with our four-item happiness measure $(r=.62)$, it did not account for our between-group differences (see Table 1). That is, both for changes in self-assessments of mood and for changes in self-assessments of ability, analyses of covariance left our "corrected" means for both ability change and mood change, as well as the relevant main effects and interaction effects, virtually unaltered in magnitude. What is more, when self-esteem was substituted for happiness as the basis for classifying participants (by means of median splits), none of the relevant main effects or interactions effects involving this variable approached statistical significance, regardless, incidentally, of whether or not happiness was included as a covariate in the relevant analyses (see Table 1).

With respect to optimism (as measured by Scheier and Carver's, 1985, Life Orientation Test), the results of our analyses were a bit more complicated (and more interesting), but the "bottom line" remained the same (see Table 2). That is, notwithstanding the undeniable association between our measures of happiness and optimism $(r=.74)$, the association of happiness with differential responses to positive versus negative social comparison information did not prove to be moderated by the optimism variable. Nevertheless, when optimism was introduced as a covariate and happiness used as the grouping variable, the $F$ ratio for the relevant interaction effect observed for mood self-assessments actually rose somewhat (i.e., from 4.87 to 6.33 ). We did find that when optimism was used as a grouping variable, it interacted with the social comparison manipulation in determining mood self-assessments, $F(1,42)=8.59, p<$ .005 ( see Table 2).

Similar results were obtained for other dependent variable measures that were examined, including participants ' retrospective assessments of mood, experimenters' assessments of negative mood, and participants' liking of the experiment. That is, the use of self-esteem as a covariate consistently had little or no impact on our measures, and its substitution for happiness

\footnotetext{
${ }^{6}$ Although such queries are understandable given the recent research emphases of individual difference work in our discipline, they are a bit ironic given the status of happiness as the individual variable most frequently cited by lay persons and savants alike over the centuries. Indeed, one might insist that self-esteem and optimism researchers have an equal obligation to demonstrate that their findings do not depend on the association of the relevant constructs with long-term happiness and its short-term manifestations.
} 
Table 1

Happiness Versus Self-Esteem in Determining Participants' Responses to Relative Success Versus Failure

\begin{tabular}{|c|c|c|c|c|c|c|}
\hline \multirow{2}{*}{$\begin{array}{l}\text { Grouping } \\
\text { variable }\end{array}$} & \multicolumn{2}{|c|}{ Low } & \multicolumn{2}{|c|}{ High } & \multicolumn{2}{|c|}{$F$ ratio for Group $\times$ Condition } \\
\hline & $M$ & Adjusted $M$ & $M$ & Adjusted $M$ & Original ANOVA & Relevant ANCOVA \\
\hline \multicolumn{7}{|c|}{ Effects on self-rated ability } \\
\hline Happiness ${ }^{\mathrm{a}}$ & & & & & $F(1,46)=1.52, n s$ & $F(1,43)=1.59, n s$ \\
\hline Slower peer & 1.15 & 1.35 & 1.55 & 1.45 & & \\
\hline Faster peer & -0.42 & -0.26 & 0.79 & 0.70 & & \\
\hline Difference & 1.57 & 1.61 & 0.76 & 0.75 & & \\
\hline Self-esteem ${ }^{b}$ & & & & & $F<1, n s$ & $F<1, n s$ \\
\hline Slower peer & 1.20 & 1.36 & 1.54 & 1.38 & & \\
\hline Faster peer & 0.09 & 0.34 & 0.43 & 0.26 & & \\
\hline Difference & 1.11 & 1.02 & 1.11 & 1.12 & & \\
\hline \multicolumn{7}{|c|}{ Effects on self-rated mood } \\
\hline Happiness $^{\mathrm{a}}$ & & & & & $F(1,44)=4.87, p<.04$ & $F(1,41)=5.66, p<.03$ \\
\hline Slower peer & 0.68 & 0.72 & 0.44 & 0.45 & & \\
\hline Faster peer & -0.48 & -0.54 & 0.15 & 0.16 & & \\
\hline Difference & 1.16 & 1.26 & 0.29 & 0.29 & & \\
\hline Self-esteem ${ }^{\mathrm{b}}$ & & & & & $F<1, n s$ & $F<1, n s$ \\
\hline Slower peer & 0.53 & 0.53 & 0.65 & 0.65 & & \\
\hline Faster peer & -0.36 & -0.37 & -0.02 & -0.02 & & \\
\hline Difference & 0.89 & 0.90 & 0.67 & 0.67 & & \\
\hline
\end{tabular}

Note. ANOVA $=$ analysis of variance $;$ ANCOVA $=$ analysis of covariance.

${ }^{2}$ Adjusted means for happiness have self-esteem as covariate. "Adjusted means for self-esteem have happiness as covariate.

as a grouping variable produced much smaller between-group differences and interactions. The use of optimism as a covariate similarly failed to eliminate the effects associated with happiness, but it did mirror some of those effects when it was used as a grouping variable. In other words, whereas self-esteem proved to have no independent predictive power in our study, optimism did prove to have some power, but neither variable mediated the reported effects associated with our simple fouritem happiness composite.

\section{Discussion}

The results of Study 1 generally supported the prediction that unhappy participants would be affected more by unfavorable social comparison information, but not by favorable information, than would happy participants. Unhappy participants who saw their peer solve anagrams faster than they expressed greater doubts about their own ability at the task, showed a greater tendency to depress their positive mood, and even reported liking the experiment less. Happy participants, by contrast, showed no such tendency to respond negatively to the unfavorable social comparison provided by their faster peer. Subsequent analysis, moreover, suggested that it was enduring differences in happiness per se, rather than the association of happiness with preexperimental mood or with the related traits of self-esteem or optimism, that accounted for the relevant differences in response.

The present research findings suggest that happy individuals may not take into account negative social comparison information when evaluating themselves, but may instead use internal standards or objective criteria as a basis for self-evaluation ( see Wayment \& Taylor, 1995, for suggestive questionnaire findings vis-à-vis high and low self-esteem; and Swallow \& Kuiper, 1990,1992 , for findings with depressed individuals). Happy individuals may also be particularly successful at ignoring or otherwise defending themselves against the potentially negative hedonic consequences of unfavorable comparisons.

In this regard, one methodological feature of Study 1 merits reemphasis. Participants in this study, who were called on to reassess their ability and report their moods after completing the anagram task, essentially had access to two different sources of new information. One source, which we did not manipulate, was provided by their own subjective experiences during the task: feelings of frustration, anxiety, enjoyment, or satisfaction, accompanied perhaps by some sense of whether they had reached, exceeded, or fallen short of their personal expectations and standards. The other source of information, which we did manipulate, was provided by the various cues that made salient to participants that their peer had solved anagrams at a much faster or slower pace than they had. What our results suggested, essentially, was that happy participants relied on the former source of information more, and the latter source of information less, than unhappy ones - at least in the condition in which they had been outperformed by their peer. That is, we really cannot determine how much participants' responses to their own performance were magnified, attenuated, or changed in direction by the peer's performance in either of the two separate social comparison conditions. We can be certain from the relevant changes only that the two groups differed significantly in their response to the presence of a faster peer and, on several measures, to the 
Table 2

Happiness Versus Optimism in Determining Participants' Responses to Relative Success Versus Failure

\begin{tabular}{|c|c|c|c|c|c|c|}
\hline \multirow{2}{*}{$\begin{array}{c}\text { Grouping } \\
\text { variable }\end{array}$} & \multicolumn{2}{|c|}{ Low } & \multicolumn{2}{|c|}{ High } & \multicolumn{2}{|c|}{$F$ ratio for Group $\times$ Condition } \\
\hline & $M$ & Adjusted $M$ & $M$ & Adjusted $M$ & Original ANOVA & Relevant ANCOVA \\
\hline \multicolumn{7}{|c|}{ Effects on self-rated ability } \\
\hline Happiness $^{a}$ & & & & & $F(1,46)=1.52, n s$ & $F(1,43)=1.28, n s$ \\
\hline Slower peer & 1.15 & 1.15 & 1.55 & 1.65 & & \\
\hline Faster peer & -0.42 & -0.44 & 0.79 & 0.85 & & \\
\hline Difference & 1.57 & 1.59 & 0.76 & 0.80 & & \\
\hline Optimism $^{b}$ & & & & & $F<1, n s$ & $F<1, n s$ \\
\hline Slower peer & 1.25 & 1.69 & 1.55 & 1.01 & & \\
\hline Faster peer & 0.08 & 0.43 & 0.50 & 0.17 & & \\
\hline Difference & 1.17 & 1.26 & 1.05 & 0.84 & & \\
\hline \multicolumn{7}{|c|}{ Effects on self-rated mood } \\
\hline Happiness $^{a}$ & & & & & $F(1,44)=4.87, p<.04$ & $F(1,41)=6.33, p<.02$ \\
\hline Slower peer & 0.68 & 0.83 & 0.44 & 0.32 & & \\
\hline Faster peer & -0.48 & -0.45 & 0.15 & 0.08 & & \\
\hline Difference & 1.16 & 1.28 & 0.29 & 0.24 & & \\
\hline Optimismb & & & & & $F(1,42)=8.59, p<.01$ & $F(1,41)=7.80, p<.01$ \\
\hline Slower peer & 0.72 & 0.70 & 0.44 & 0.48 & & \\
\hline Faster peer & -0.55 & -0.57 & 0.29 & 0.31 & & \\
\hline Difference & 1.27 & 1.27 & 0.15 & 0.17 & & \\
\hline
\end{tabular}

Note. $\quad$ ANOVA $=$ analysis of variance; ANCOVA = analysis of covariance.

${ }^{a}$ Adjusted means for happiness have self-esteem as covariate. ${ }^{b}$ Adjusted means for self-esteem have happiness as covariate.

faster peer versus slower peer manipulation. In the second study to be reported, which included a no-social-comparison control, we provide some further evidence about relative sensitivity and insensitivity to feedback about own versus peer performance under conditions of potentially ego-suffering and ego-deflating peer performance. But even in the absence of such control group data to sharpen conclusions, Study 1 leaves little doubt that happy and unhappy individuals differ in one of the most fundamental and thoroughly studied aspects of self-assessment, that is, the incorporation of social comparison information. A more specific implication relevant to affect also seems clear. In a world in which we all are bound to encounter peers faster, more clever, or more successful than uurselves, happy individuals are apt to prove less vulnerable in their day-to-day self-assessments and feelings of well-being than their unhappy neighbors.

Study 2 again examined the responses of self-rated unhappy and happy participants to social comparison information, but the experimental design and procedures were very different from those used in Study 1. Participants first performed a novel teaching task, then received explicit "expert" feedback about either their own "positive" or their own "negative" performance, either unaccompanied by any social comparison information or accompanied by feedback suggesting that a peer had performed even better or even worse at the same teaching task. Our working hypothesis, again, was that happy participants would be less influenced than unhappy participants by social comparison information in general, and that this difference would be particularly pronounced in conditions in which the participants learned that although they had done well, their peer had done even better.
Study 2

Method

\section{Overview}

In a study purportedly on the effectiveness of television teaching, pairs of participants were asked to use hand puppets to teach children about conflict resolution while their performances supposedly were being evaluated by a graduate student observing them one-at-a-time from behind a one-way mirror. Participants in the no-social-comparison condition subsequently received feedback about their own performance, in the form of ratings from the expert suggesting that it had been either highly satisfactory or somewhat unsatisfactory, but no information about the performance of their peer. Social comparison condition participants received similar positive or negative performance feedback but were further led to believe, through a subtle manipulation, that their peer had performed even better or even worse. All participants ultimately completed questionnaires regarding their moods, self-confidence, and perceptions of ability on three occasions: at the beginning of the experimental session, after performing the teaching task but before receiving any feedback about their performance, and finally, after hearing the performance evaluations that constituted our main experimental manipulation.

\section{Participants}

A total of 81 introductory psychology students at Stanford University ( 37 women and 44 men) received course credit for participating in this study. Prior to the experimental session, participants completed the same four Likert-type measures of happiness used in Study 1, once again as part of a larger packet of unrelated questionnaires. As in previous studies (e.g., Lyubomirsky, 1994; Lyubomirsky \& Ross, 1997), students whose 
composite scores were either in the upper or lower quarter of the distribution ( $m d n=5.75$; possible scores ranged from 1.0 to 7.0 ) were recruited for the happy and unhappy groups, respectively. A total of 42 participants (19 women and 23 men) ultimately constituted the happy group ( $M=$ $6.19, S D=0.36$ ), and 39 participants ( 18 women and 21 men) constituted the unhappy group $(M=2.98, S D=0.74)$.

\section{Procedure and Materials}

Participants were run in pairs, ostensibly "just to save time" but in actuality to permit the experimental manipulation of social comparison information. Each pair always consisted of participants with the same happiness status, to which the experimenter was blind. On arriving at the designated experimental room, participants were told that they would be taking part together in a study on the use of closed-circuit television for teaching young children. This purported rationale focused participants' attention and motivation on the matter of teaching ability and performance without alerting them to the researchers' interest in happiness. Participants were led to believe that we would be comparing the performances of people who previously had enjoyed little teaching experience (that is, college undergraduates like themselves) with performances of seasoned primary education teachers. Accordingly, participants were told, they would be asked to take turns teaching a lesson to an intended audience of 6- to 7-year-olds, which would be filmed for later use but also observed and evaluated immediately by a graduate student expert.

After reading and signing a consent agreement, participants received a preliminary questionnaire in which they were asked to characterize their baseline mood and assessments of their teaching ability. Participants rated how tense, secure, happy, motivated, and depressed they currently were feeling, using 7-point Likert-type scales $(1=$ not at all; $7=a$ great deal). They also used similar scales to rate how good they thought they were at teaching $(1=$ very poor; $7=$ excellent $)$. To bolster this purported rationale, participants were also asked to respond to a number of filler items dealing with their previous teaching or tutoring experiences and their degree of interest in a teaching career.

On completing these preliminary measures, the two participants in turn (with order randomly assigned) separately received instructions and proceeded to undertake the teaching task while the other participant waited in a separate room. Participants were told that they would be teaching in front of a one-way screen (i.e., without any opportunity to see or interact with their students, as in real television teaching), while their performance was recorded by a video camera, ostensibly for later analyses and evaluations. They also were told that a graduate student expert would sit on the other side of the screen and provide an immediate evaluation of their live performance. Thereupon, participants met the socalled expert, saw the video camera (which, incidentally, was never actually turned on), and were led into the teaching room, where they were fitted with a clip-on microphone that seemingly was wired into the adjoining room.

Participants then were given two cloth hand puppets, an otter and a squirrel, and were told that their task was to use the puppets as aids in teaching an intended audience of 6- to 7-year-olds how to resolve a conflict arising from the fact that "Squirrel had borrowed a toy from Otter without asking Otter's permission and then accidentally broke it, which made Otter very angry." Before beginning their teaching session, however, participants were told that one of the two members of each pair would wear a red T-shirt and the other would wear a green Tshirt (supposedly for later coding and identification). Accordingly, each subject was first to turn over the top card of a stack of cards to learn what color T-shirt he or she had been assigned. This draw, which took place after the experimenter had left the room, was contrived so that all participants learned that they had been assigned the red $\mathrm{T}$-shirt. This procedure facilitated a later manipulation in which participants received feedback either about only the red-shirted teacher (i.e., them) or about the green-shirted teacher (i.e., their supposed peer) as well.

The preparation period lasted approximately $2 \mathrm{~min}$. When that period was completed, the experimenter knocked on the door, signaling the participant to begin teaching the lesson, which lasted exactly $5 \mathrm{~min}$.

While the participant was performing the teaching task, the supposed graduate student expert, actually a confederate of the experimenter, rated the participant's apparent level of anxiety and dysphoria, using 7-point Likert-type scales ( $1=$ not at all; $7=a$ great deal $)$. She also evaluated participants on apparent overall happiness $(1=$ not a very happy person; $7=a$ very happy person), how much they seemed to be enjoying the task $(1=$ not at all; $7=a$ great deal $)$, how well they seemed to be performing ( $1=$ very poor; $7=$ excellent $)$, and how comfortable they seemed with the task $(1=$ not at all $; 7=$ a great deal $)$.

Immediate postperformance (prefeedback) questionnaire. After undertaking the teaching task, participants completed a short questionnaire in which they used 7-point Likert-type scales to rate how much they enjoyed the task ( $1=$ not at all; $7=$ a great deal $)$, how well they thought they had done on the task $(1=$ very poor; $7=$ excellent $)$, and how good a teacher they felt they had been $(1=$ very poor; $7=$ excellent). They also used similar scales to indicate their immediate mood, that is, how good, sad, and confident they currently were feeling. The first two of these mood ratings were combined into a single index of positive mood $(\alpha=.82)$, whereas the confidence rating was analyzed separately.

Social comparison manipulation. In the no-social-comparison conditions, participants received subsequent feedback separately and heard evaluations of only their own performances. The experimenter brought each participant, in turn, into a separate room and, as promised, conveyed the graduate student expert's feedback about that participant's performance, which the graduate student had witnessed from behind the one-way glass. More specifically, the experimenter produced the expert's evaluation form, prominently bearing the label "red" (because, it be recalled, all participants believed that they alone had worn the red shirt during the teaching performance and that their peer had worn the green shirt). The form consisted of three pages of detailed but inauthentic ratings, including types of smiles and facial expressions, verbal usage, voice quality, signs of nervousness, and types of puppet movements. The last page of the form, which the experimenter read and explained to the participant, listed five dimensions of performance (i.e., communication skill, ability to capture the 6-to 7-year-olds' attention, comprehensibility, level of comfort, and potential impact on the relevant audience) and provided evaluations for each of those dimensions, as well as an overall rating of performance $(1=$ poor $; 7=$ spectacular $)$. In positive feedback conditions, the participants learned that they had received ratings ranging from very good to excellent on the individual dimensions, with an overall rating of 6 . In negative feedback conditions, the participants learned that they had received "fair" or "less than fair" marks on the individual dimensions, with an overall rating of 3.5 .

In the social comparison conditions, by contrast, the experimenter provided feedback to each pair of participants together, brandishing the relevant evaluation forms, one clearly labeled "red" and the other labeled "green." In positive feedback conditions, both participants heard performance evaluations suggesting that the red-shirted teacher (which both participants believed to have been themselves) had received ratings ranging from very good to excellent on the individual dimensions, with an overall rating of 6 on the 7-point scale, whereas the green-shirted teacher ( which both believed to have been the other) had received ratings ranging from excellent to spectacular on the individual dimensions, with an overall rating of 7 . In negative feedback conditions, the participants heard evaluations suggesting that whereas the red-shirted teacher earned only average or slightly below average marks on the individual dimensions, with an overall rating of 3.5 on the 7-point scale, the green-shirted teacher had generally received poor marks on the individual dimensions. 
with an overall rating of only 2 . In other words, the positive feedback condition participants believed that although they had done well their peer had done even better, and the negative feedback condition participants believed that although they had done poorly their peer had done even worse.

Postfeedhack questionnaires. Immediately after having received feedback, all participants completed a final questionnaire that included another mood inventory in which they used 7-point Likert-type scales to rate how happy, down, and adequate they were currently feeling. The first two mood ratings were subsequently combined into a single index of positive mood ( $\alpha=.84$ ), whereas the rating of adequacy was used as an indicator of self-confidence. To evaluate changes in participants' perceptions of ability following feedback, we also asked them once again to rate their performance on the teaching task $(1=$ very poor; 7 $=$ excellent . .

We assessed the effectiveness of the social comparison manipulation by having participants in the social comparison conditions rate how the other participant had been evaluated relative to them $(1=$ much better; $2=$ a little better; $3=$ same; $4=$ a little worse; 5 = much worse; or don't remember). These participants also rated how they felt upon hearing the evaluations of their own performance $(1=$ very bad; $7=$ very good). Participants in the no-social-comparison condition, by contrast, were asked to guess how the other participant had been evaluated relative to them and to rate how they felt when they heard the evaluation of their own performance. In order to bolster further the purported rationale of the study, we also asked participants in both conditions to respond to several filler items about their perceptions and feelings about the teaching task and teaching in general.

Finally, all participants completed the debricfing questionnaire in which they were given an opportunity to voice any suspicions or concerns about the study. Their responses on a debriefing questionnaire and their comments during oral debriefing indicated that the cover story had been successful in minimizing the role of possible experimental demand characteristics. That is, no participant reported having guessed the purpose of the study or the link between this study and the four ratings of happiness completed several weeks earlier. Participants were then given a thorough process debriefing to minimize any long-term impact of the false feedback manipulation (see Ross, Lepper, \& Hubbard, 1975). The entire procedure took approximately $1 \mathrm{hr}$.

\section{Results}

Preliminary analyses indicated no main effects or interactions involving participant gender. Accordingly, this variable was ignored in subsequent analyses and presentation of results (although the absence of such gender differences is worth noting, and is reassuring, in view of our exclusive reliance on female participants in Study 1).

\section{Manipulation Checks}

The manipulation of positive versus negative feedback, in the absence of any information about peer performance, was effective in influencing participants' ratings of their own performances. That is, those participants in the no-social-comparison condition who were told that they had done well later rated their own performance as significantly better $(M=3.78, S D=1.22)$ than those told that they had done poorly $(M=2.75, S D=$ $1.45), F(1,73)=6.41, p<.02$. The manipulation of social comparison information was similarly effective. When asked to indicate how the feedback given to the other participant compared to their own feedback (using a 5-point scale where 1 = a lot worse, and $5=$ a lot better), participants who learned they had done well but their peer had done even better gave that peer a mean rating of $4.10(S D=0.31)$, whereas participants who learned they had done poorly but their peer had done even worse gave that peer a mean rating of $1.95(S D=0.22$ ), $t(34)=25.27, p<.0001$. Participants who had not received any explicit social comparison information, by contrast, guessed that their peer had received feedback slightly more positive than their own feedback - not only in the positive feedback condition ( $M=3.21, S D=0.89)$ but in the negative feedback condition as well $(M=3.55, S D=0.96), t(29)=1.12, n s$.

\section{Premanipulation Ratings}

Happy and unhappy participants filling out self-rating scales prior to beginning the study differed significantly on only two items. First, consistent with the results of the previous study, happy participants reported more positive moods at the beginning of the study $(M=5.33, S D=0.93)$ than did unhappy participants $(M=4.75, S D=0.89), t(78)=2.86, p<.006$. Second, happy participants reported more prior experience working with children $(M=4.57, S D=1.67)$ than did unhappy participants $(M=3.85, S D=1.55), t(78)=2.03, p<.05$ (a difference that presumably should have led happy participants to hold higher expectations about their teaching performance and, presumably, to experience more disappointment in the face of any subsequent negative feedback). Happy and unhappy participants, however, did not differ significantly in premanipulation self-assessments of their teaching ability $(M \mathrm{~s}=3.82$ and 3.79 , respectively).

\section{Participants' Actual Performance and Initial Self-Assessments}

In contrast to the anagram-solving task in Study 1, the teaching task in the present study offered no simple or objective performance measures. Subjective assessments of performance, however, were made by the experimental confederate (unaware of participants' group or feedback condition), who observed each participant's performance from behind a one-way screen. These ratings revealed that the performances of happy participants were, in fact, judged somewhat superior, on average ( $M$ $=4.93)$, to those of unhappy participants $(M=4.29), t(76)$ $=2.45, p<.02$. Happy participants were also judged by the confederate to be enjoying the task more ( $M=4.69$ vs. 4.04 ), to be more comfortable with the task ( $M=4.62$ vs. 3.74$)$, and to look less anxious and discouraged ( $M=1.94$ vs. 2.37 ), and in fact to be happier ( $M=4.50$ vs. 4.04 ) than unhappy participants (all $p$ s significant at the .05 level). The happy participants' immediate self-assessments (prior to receiving any feedback from the expert observer) similarly were consistently more positive than those of unhappy participants. That is, happy participants reported more positive moods $(M=5.25 \mathrm{vs.} 4.31)$ and greater self-confidence ( $M=4.31$ vs. 3.23 ) than unhappy participants. They also reported enjoying the task more $(M=4.02$ vs. 2.87), performing better on the task ( $M=3.00$ vs. 2.10 ), and feeling like a better teacher $(M=3.67$ vs. 2.68; all $p \mathrm{~s}<.05)$. 


\section{Postfeedback Assessments}

After receiving feedback in the four relevant conditions, happy participants overall reported more positive moods $(M=$ 5.34 vs. 4.49$)$, greater self-confidence ( $M=4.63$ vs. 3.58 ), and more positive perceptions of their teaching performance ( $M$ $=3.29$ vs. 2.51 ) than did unhappy participants. These main effects for happiness status were all significant at the .01 level or better.

What was of primary interest in this study, however, were the various changes in ratings shown by happy and unhappy participants after receiving positive or negative feedback about their own performance feedback, either unaccompanied by social comparison information or accompanied by information suggesting that their peer had done even better or even worse. Following the results of Study 1, it had been hypothesized that happy participants would be less influenced by social comparison feedback than unhappy participants, both in their affective responses and in their self-evaluations. This difference, it was further expected, would be especially apparent in conditions in which participants learned that their own performance, although excellent, had been surpassed (at least in the eyes of the expert evaluator) by the performance of their peer. These hypotheses were tested in two ways: through separate planned pairwise comparisons between relevant conditions (Rosenthal \& Rosnow, 1985; see also Rosnow \& Rosenthal, 1989) and through calculations of interaction effects among group (happy vs. unhappy), feedback type (positive vs. negative), and comparison type (social comparison vs. no social comparison). To pursue these findings we performed statistical analyses that both examined simple change scores between postteaching ratings and postfeedback ratings and treated preexperimental ratings as covariates. To avoid redundancy and facilitate exposition, we discuss only change score results. ${ }^{7}$ Self-ratings of teaching performance, composites of positive mood ratings, and composites of selfconfidence ratings constituted the main dependent variables in this study.

Self-assessments of teaching performance. Examination of changes in participants' evaluations of their own teaching performances following feedback revealed only a main effect of feedback positivity. That is, participants who received positive feedback increased ratings of their teaching performance $(\bar{\Delta}=$ +1.19 ) more than did participants who received negative feedback $(\bar{\Delta}=+0.22), F(1,73)=21.62, p<.0001$. No other main effects or interaction effects reached conventional significance levels. In other words, the addition of social comparison information suggesting that a peer had done even better or even worse had little if any impact on the participants' assessments of their teaching performance; happy and unhappy participants alike gave weight only to the supposed expert's evaluation of their own performance, with no recalibration reflecting what they had learned about the expert's evaluation of someone else.

Self-assessments of positive mood. In view of the lack of group differences or interaction effects vis-à-vis self-ratings of performance, differences and interaction effects observed in self-ratings of mood become all the more interesting. And such differences were in fact found. First, although the experts' positive performance feedback significantly boosted participants' moods overall $(\bar{\Delta}=+0.67), t(40)=4.38, p<.0001$, it influenced happy and unhappy participants' moods differently as a function of the participants' feedback condition ( see Figure 2 ). That is, in the case of happy participants, positive feedback boosted their moods regardless of whether it was the only information received ( $\bar{\Delta}=+0.85$ ) or was accompanied by social comparison information that a peer had done even better $(\bar{\Delta}=$ $+0.98)$ ( $F<1$ for the relevant pairwise comparison). In the case of unhappy participants, by contrast, the same positive feedback boosted their moods only in the absence of such social comparison information ( $\bar{\Delta}=+1.01)$. In fact, unhappy participants who learned that their peer had received even more positive feedback than they reported a slight drop in $\operatorname{mood}(\bar{\Delta}=-0.17)$, $F(1,73)=7.16, p<.01$, for the pairwise comparison. In other words, the information that a peer had outperformed them considerably attenuated the impact of the apparent success for unhappy participants but had no such effects for happy participants. This pattern of results was further reflected in a significant Group (happy vs. unhappy) $\times$ Comparison Type (peer even better vs. peer even worse) interaction within the positive feedback condition, $F(1,36)=5.81, p<.03$.

The impact of negative feedback from the expert and the buffering effect of hearing the peer receive even more negative feedback was apparent for both groups. Not surprisingly, negative feedback delivered in the absence of any social comparison information made happy and unhappy participants alike report less positive moods than they had reported before receiving such feedback. More surprising, perhaps, this decrease was slightly, albeit not significantly greater for happy $(\bar{\Delta}=-0.91)$ than for unhappy $(\bar{\Delta}=-0.20)$ participants, $F(1,73)=2.69, p<.15$. The presence of a peer receiving more negative information than they offered solace to participants in both groups. Happy participants provided with such comforting social comparison information showed virtually no decline in $\operatorname{mood}(\bar{\Delta}=-0.09)$, and unhappy participants actually showed a marked elevation of $\operatorname{mood}(\bar{\Delta}=+0.75)$. The Group $\times$ Comparison Type interaction within the negative feedback condition was not statistically significant $(F<1)$.

Although the net buffering effect of the social comparison information accompanying negative feedback about one's own performance was of roughly equal magnitude in the two groups, the overall pattern of results seen when we consider all eight conditions is highly revealing (again, see Figure 2). Unhappy participants, we find, actually showed more positive mood (relative to their preexperimental baseline) on receiving a negative evaluation accompanied by the news that their peer had done even worse $(\bar{\Delta}=+0.75)$ than on receiving a positive evaluation accompanied by the news that their peer had done even better $(\bar{\Delta}=-0.17), F(1,73)=4.81, p<.03$. By contrast, happy participants' moods were considerably elevated by the news that

\footnotetext{
${ }^{7}$ It should be emphasized, however, that covariance analyses, which used premanipulation ratings as the covariate and postmanipulation ratings as the dependent variable, yielded results very similar to those obtained using the analyses of simple change scores. This finding is especially relevant in light of the differences between happy and unhappy participants apparent in self-assessments of performance and mood immediately following the teaching task. In addition, preliminary analyses using premanipulation mood as the covariate yielded results that were virtually identical to those reported.
} 


\section{Feedback Condition}

Positive; No Peer Feedback

Positive; Peer Even Better
Negative; No Peer Feedback

Wegative; Peer Even Worse
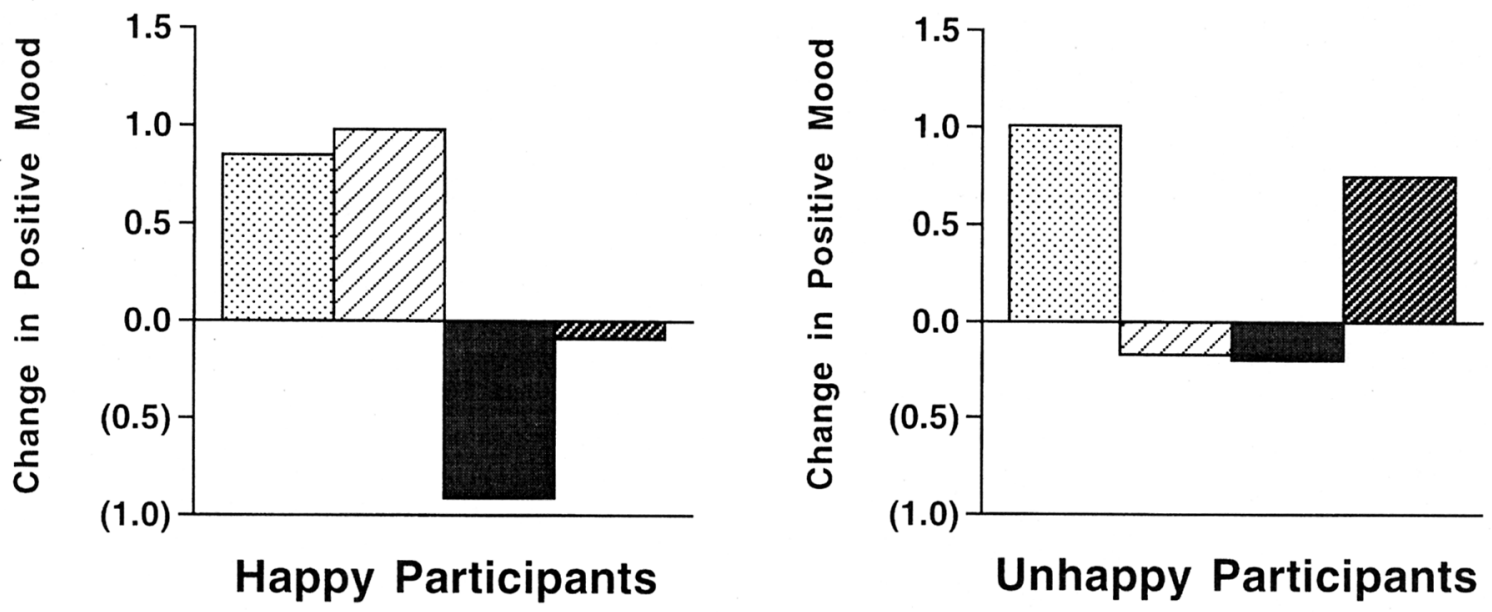

Figure 2. Changes in positive mood (Study 2).

although they had done well, their peer had done even better $(\bar{\Delta}=+0.98$ ) and were slightly deflated by the news that they had done poorly but that their peer had done even worse $(\bar{\Delta}=$ $-0.10)$. This overall pattern of results was reflected in three interaction effects: a Group $\times$ Feedback Type (positive vs. negative) interaction, $F(1,73)=8.85, p<: 004$; a Comparison Type $\times$ Feedback Type interaction, $F(1,73)=10.88, p<.002$; and a marginal Group $\times$ Feedback Type $\times$ Comparison Type interaction, $F(1,73)=2.88, p<.095$.

Self-assessments of confidence. A similar pattern of results, displayed in Figure 3, was found for changes in ratings of selfconfidence, although it was obscured somewhat by the tendency for participants in all groups and conditions to show increased confidence after undertaking the teaching task. Thus, happy participants' self-confidence was enhanced considerably by positive feedback regardless of whether such feedback was provided alone $(\bar{\Delta}=+2.46)$ or was accompanied by the information that their peer had performed even better $(\bar{\Delta}=+2.90), F<$ 1. By contrast, unhappy participants' self-confidence was enhanced significantly by positive feedback delivered alone $(\bar{\Delta}=$ +2.89 ), but only minimally when accompanied by the information that their peer had done even better $(\Delta=+0.50), F(1$, 73 ) $=10.35, p<.002$, for the comparison between these two means. Negative feedback appeared to have exerted rather similar effects on self-confidence for the two groups, both in the presence and absence of social comparison information; that is, happy and unhappy participants alike showed modest increases in self-confidence both in peer feedback and no-peer-feedback conditions. Once again, however, the overall pattern of results that emerged was striking in that unhappy participants showed greater increases in self-confidence after learning that they did poorly but their peer did even worse $(\bar{\Delta}=+1.82)$ than after learning that they did very well but their peer did even better $(\bar{\Delta}=+0.50), F(1,73)=3.48, p<.07$, whereas happy participants showed smaller increases in self-confidence in the latter condition $(\bar{\Delta}=+1.20)$ than in the former condition $(\bar{\Delta}=$ $+2.90), F(1,73)=5.53, p<.03$. This pattern of mean changes for happy and unhappy participants again was reflected in three interaction effects: a significant Group $\times$ Feedback Type interaction, $F(1,73)=3.96, p=.05$; a marginal Group $\times$ Comparison Type interaction, $F(1,73)=3.01, p<.09$; and a significant Group $\times$ Feedback Type $\times$ Comparison Type interaction, $F(1$, $73)=4.84, p<.04$.

\section{Discussion}

Corroborating the results of Study 1, happy participants again appeared to be less sensitive to potentially unwelcome social comparison information than did unhappy participants. This difference, however, was apparent only in the participants' moods and self-confidence ratings; it was not apparent in their selfassessments of ability. In the case of positive performance feedback, the knowledge that a peer had received even more positive feedback greatly attenuated the positive reactions of self-rated unhappy participants but did not attenuate those of happy participants. In the case of negative performance evaluations, both groups' moods were buffered by the knowledge that their peer had received even more negative feedback. The net result, as we have reported, was that unhappy participants reported more positive changes in mood and self-confidence on receiving a poor performance evaluation and hearing their peer receive a worse one than on receiving an excellent evaluation and hearing 
Feedback Condition

Positive; No Peer Feedback

Positive; Peer Even Better
Negative; No Peer Feedback

У Negative; Peer Even Worse
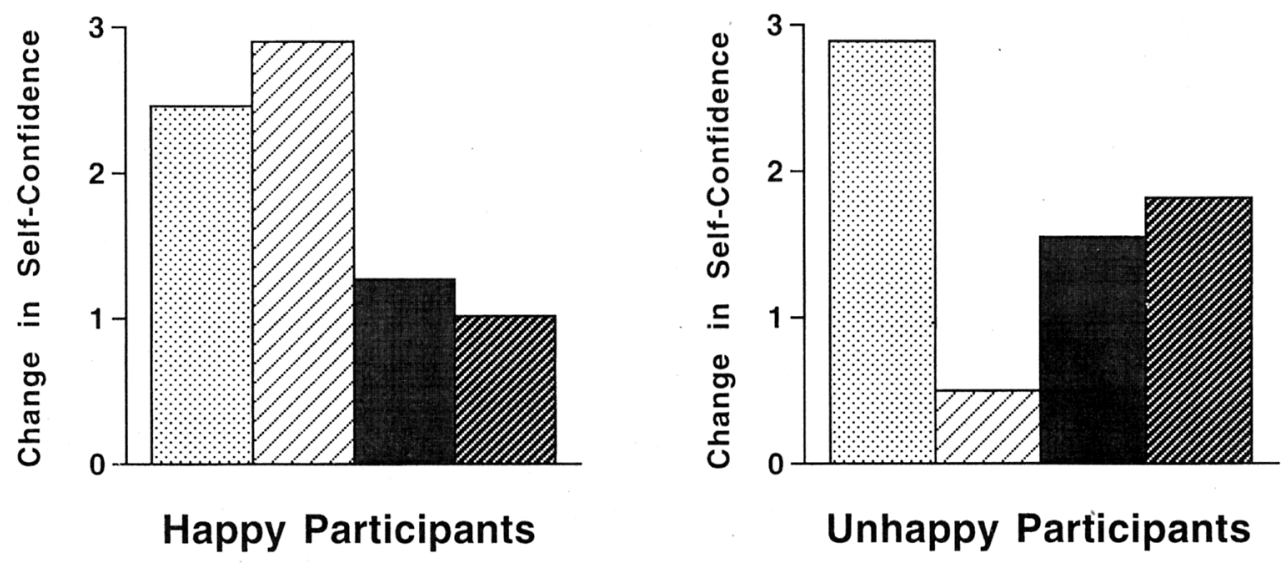

Figure 3. Changes in self-confidence (Study 2).

their peer receive a better one. Happy participants, by contrast, seemed to be governed more by their own outcomes and less by the relevant social comparison information. It is worth reemphasizing that happy and unhappy participants in Study 2 were similarly responsive to expert feedback about their own performances. In fact, there was some evidence that happy participants were slightly more sensitive to negative feedback than were unhappy participants (a result that makes one wonder whether they were simply less accustomed to receiving such feedback). Again, it was primarily in the relative weight given to negative social comparison information that the two groups differed.

Why were group differences in response to potentially unwelcome social comparison not found for self-assessments of ability in Study 2, whereas they were found for such assessments in Study 1? A possible explanation for the discrepancy between these two sets of findings may lie in the different types of feedback received by participants in the two studies. Whereas Study 2 provided participants with explicit expert assessments of their own particular performances, Study 1 provided essentially no external feedback, or at least none that could be separated from the social comparisons furnished by a faster or a slower peer. Consequently, Study 2 simply may have left participants with less attributional latitude in judging their own abilities. The latitude that remained for Study 2 participants was in their affective responses to the relevant feedback, and it was in self-ratings reflecting these affective responses that differences between happy and unhappy groups were to be found.

\section{General Discussion}

Confirming our most general hypothesis, happy people in both studies proved to be less responsive to potentially negative social comparison information than were unhappy people. How and why did happy participants protect themselves against the potentially negative hedonic consequences of an unfavorable social comparison? One possibility, of course, is that they gave such information very little weight--hardly an unreasonable thing to do in contexts such as those of Study 1 and Study 2, where the comparison source was a single, perhaps highly unrepresentative peer (see also Ahrens, 1991). It remains to be determined whether happy individuals would continue to be less heavily influenced than unhappy individuals, either in their self-evaluations or moods, by more diagnostic social comparison information, for example, information about their standing relative to the majority of their peers.

A related possibility is that the happy participants in our study possessed relatively firm convictions about their own efficacy, buttressed perhaps by their subjective experiences while performing the relevant tasks, so that they had little uncertainty to resolve through social comparison (see J. D. Campbell, 1990; Kernis, Cornell, Sun, Berry, \& Harlow, 1993, for relevant findings vis-à-vis high self-esteem individuals). Unhappy participants, by contrast, may have been less certain about the absolute or relative level of their abilities, more concerned with their peer's outcomes, or less inclined to attribute the gap between their own performance and that of their peer to their own limitations. It is even possible, in light of our present findings on mood, that happy individuals may be more inclined than unhappy ones to view their abilities as malleable rather than fixed (see Dweck, 1986; Dweck \& Leggett, 1988), such that a peer's superior performance constitutes not a threat but an incentive, and an indication of their own prospects for improvement and future success. Our present data obviously do not allow us to 
distinguish among these alternatives. They merely permit us to rule out the possibility that happy people are simply oblivious to feedback in general or to social comparison information in particular.

Our results further suggest that happy and unhappy individuals may differ, in a manner consistent and supportive of their affective states and dispositions, in their use of social comparison information. By using social comparison information strategically, our happy participants thus may maintain and even increase their prospects for longer-term happiness and well-being (not to mention their prospects for improved future performances). By giving heavy, and arguably undue, weight to social comparison information in general, and negative social comparison in particular, our unhappy participants responded in a way that may increase their vulnerability and perhaps even diminish their happiness. Possibilities of negative social comparisons with friends, mates, and colleagues (not to mention characters from Lifestyles of the Rich and Famous') are ubiquitous in everyday life (e.g., Gilbert, Giesler, \& Morris, 1995). Such comparisons may be misleading and destructive. Feeling dejected as a result of other people's successes and taking satisfaction from their failures, seems a poor prescription for happiness (and an even poorer strategy for winning friends and influencing people). Attending primarily to one's own outcomes, acknowledging others' successes without envy, and taking little satisfaction in their failures seems to offer a better prescription for wellbeing.

The strategy of paying heed to or ignoring social comparison information, it is worth reiterating, has implications for the stability of self-esteem and emotional life. It is important, therefore, to note some recent data from our laboratory suggesting that individuals who show high variability in their daily moods are, in fact, more likely to report themselves as chronically unhappy (Lyubomirsky, 1994). Furthermore, there is evidence that those who have more poorly articulated, uncertain, and unstable self-concepts are more likely to have low self-esteem (J. D. Campbell, 1990); those who are emotionally reactive to daily stress are more likely to score as characteristically neurotic (Heatherton \& Polivy, 1991); and those easily influenced by daily uplifts, problems, and setbacks are more prone to clinical depression (Butler, Hokanson, \& Flynn, 1994). However, people who rely primarily on personal, internal, or objective information as a basis for their self-evaluations and largely ignore comparisons with others may be spared one important source of such setbacks. In a sense, they are shielded from some aspects of external reality, especially aspects over which they have very little control, and may as a result show less variable moods and more stable self-concepts, and greater overall happiness and contentment.

Our discussion thus far naturally brings us to consider the relationship between happiness and self-esteem. The emerging picture of the happy person is one of an individual who has a solid, stable, and consistent self-image, one that is relatively resistant to others' standards or to daily ups and downs. The picture of the unhappy person is that of an individual with highly sensitive antennae tuned to detect any information that possibly bears on one's abilities and outcomes, a state of heightened sensitivity that portends a relatively unstable and uncertain sense of self-worth in many, if not all, evaluative domains. It remains for further research to determine whether it is the level or the lability of one's self-esteem that is more closely related to subjective happiness and well-being. Our own hunch, based on everyday observation of our peers, is that high, even consistently high, self-esteem will prove a necessary condition, but not a sufficient one, for happiness and well-being. In other words, although we expect research to reveal few low-self-esteem individuals who are generally happy, we expect to find plenty of bigh-self-esteem individuals who are chronically unhappy, or at least less happy than their objective circumstances would seem to warrant. We remind our readers, in any case, that our present findings were not mere reflections of any direct association between happiness and self-esteem.

The question also inevitably arises as to whether it is happiness that promotes a relative insensitivity to social comparisons, or whether it is insensitivity that promotes happiness. This question bears not only on the relationship between enduring happiness and social comparison processes but on the more general question of the association between cognitive biases and affective states. There is reason to believe, both from research experience and anecdotal evidence, that the influence is bidirectional (e.g., Ekman \& Davidson, 1994; Fiske \& Taylor, 1991; Forgas, 1995; Wegner \& Pennebaker, 1993). Happy people may pay less attention to social comparisons; consequently, they experience immediate hedonic rewards, which ultimately contribute to their sense of overall well-being. Unhappy people, by contrast, may dwell on social comparisons, a strategy that diminishes their self-esteem and their moods and ultimately contributes to even greater unhappiness. It is possible that a feedback loop thus develops between enduring happiness, immediate hedonic consequences (such as transient affect and self-esteem), and responses to social comparisons. Future research could shed light on the nature of this process and the mechanisms that underlie it by examining the various links in this chain. Studies that attempt to manipulate social comparison processes (e.g., by encouraging participants to place great weight on or to discount social comparison information ) and observe the effects on participants' moods and self-evaluations would be especially useful in this endeavor.

\section{Caveats, Alternative Interpretations, and Future Research Directions}

It is tempting to consider the relationship of our findings to self-verification theory (Swann, 1983; Swann, Wenzlaff, Krull, \& Pelham, 1992) or even dissonance theory (Aronson, 1969; Festinger, 1957). One could argue that our participants simply attended to information, interpreted it, and assigned it weight as a function of its congruity with their beliefs about their capacities, or even its compatibility with their affective state (although the reader should be reminded that it was participants' enduring happiness status, rather than their mood at the time of the study, that predicted their responses to the relevant experimental manipulations). Some of our specific findings clearly are compatible with this view, particularly the tendency for unhappy anagram solvers and teachers to give greater weight than their happy peers to negative social comparison information. But other findings seem less compatible with this selfverification view. Most notably, unhappy participants seemed to 
thoroughly embrace rather than disregard social comparison information that served to remove the sting of their own negative performance feedback. Furthermore, happy participants did not ignore or remain unmoved by explicit negative feedback about their own performances; it was only potentially ego-deflating social comparisons that failed to dampen their mood or selfregard. Finally, and perhaps most significant, although happy and unhappy participants differed in their initial moods, they did not differ in their preexperimental assessments of their taskrelevant abilities.

It is also worth considering the extent to which response differences between happy and unhappy participants may have been mediated by differences in their transient moods at the time of each study. There is abundant evidence, after all, that levels of long-term happiness are associated with greater positivity of transient mood (e.g., Lyubomirsky, 1994; Lyubomirsky \& Ross, 1997; Seidlitz, Wyer, \& Diener, 1997). Indeed, in the two studies reported in this paper, happy participants did report more positive moods at the beginning of each session than did unhappy participants. Controlling for these initial group differences in mood through covariance analysis, however, did not significantly change our results. Although such statistical procedures cannot definitively rule out the mood-as-mediator hypothesis, we can also take note of some recent findings from our laboratory (Lyubomirsky, 1994). To wit: Although both moodelevating and mood-depressing manipulations affected the selfassessments of both groups, they did not eliminate betweengroup differences.

A more serious source of concern in these studies was the exclusive reliance on self-report measures to characterize our participants' enduring happiness. As a result, the independent measures used (i.e., self-ratings of absolute happiness and wellbeing and status on these variables relative to one's peers) and the dependent variable measures (i.e., self-assessments of mood, self-confidence, and ability) may have been subject to shared sources of bias or confounding. Every researcher who has studied happiness has had to grapple with the problem of how to measure this seemingly elusive and intangible construct (cf. Argyle, 1987; Diener, 1994; Freedman, 1978; Myers \& Diener, 1995 ) and how to distinguish it from related but distinctly different concepts such as self-esteem, optimism, depression, extroversion, and the like. Since no "happiness thermometer" exists, the presently used technique of self-nomination (buttressed somewhat by peer nominations and observer ratings) seemed, in spite of its limitations and potential sources of confounding, the best available solution to the measurement problem. Moreover, given that the research concerns subjective happiness and well-being, it seems appropriate that the ultimate judge of happiness must remain the person whose temperament is being assessed (Myers \& Diener, 1995). In any case, it is worth noting that any weakness or unreliability in the measures of happiness used would presumably serve to increase error variance, or "noise," and thus would tend to obscure differences that might be seen more clearly with more discriminating measures of happiness. In a sense, the emergence of such clear and consistent differences between groups designated in a relatively crude and potentially noisy fashion may be testimony to the magnitude and robustness of the relevant effects.

Our present findings, we should note in closing, corroborate and extend data from collateral studies in our laboratory showing the self-assessments and moods of unhappy individuals to be more reactive than those of happy ones to the outcomes of both trivial choices and important life decisions (Lyubomirsky \& Ross, 1997). Together, these findings suggest that unhappy people may react as if all outcomes are fraught with hedonic consequences, whereas happy people are more selective in their reactions. It is thus worth emphasizing again the links between hedonic consequences and the various cognitive processes and biases that social psychologists have explored for decades. The hedonic consequences of many much-studied cognitive and judgmental processes-dissonance reduction, psychological reactance, the "hedonic treadmill," the framing of events-are sometimes positive, sometimes negative, and sometimes even mixed or uncertain. Our most general hypothesis, that individual differences in hedonic functioning would be linked to particular cognitive and motivational strategies and biases, thus remains a topic for continuing examination. Such research promises to yield insights both about the nature of happiness and well-being and about the complex links between affect and cognition.

\section{References}

Ahrens, A. H. (1991). Dysphoria and social comparison: Combining information regarding others' performances. Journal of Social and Clinical Psychology, 10, 190-205.

Andrews, F. M., \& Withey, S. B. (1976). Social indicators of well. being. New York: Plenum Press.

Argyle, A. M. (1987). The psychology of happiness. London: Methuen.

Aronson, E. (1969). A theory of cognitive dissonance: A current perspective. Advances in Experimental Social Psychology, 2, 21-34.

Aspinwall, L. G., \& Taylor, S. E. (1993). Effects of social comparison direction, threat, and self-esteem on affect, self-evaluation, and expected success. Journal of Personality and Social Psychology, 64, $708-722$.

Beck, A. T., \& Beamesderfer, A. (1974). Assessment of depression: The depression inventory. In P. Pichot (Ed.), Psychological measurements in psychopharmacology and modem pharmacopsychiatry ( $\mathrm{pp} .151$ 169). Basel, Switzerland: Karger.

Beck, A. T., \& Beck, R. W. (1972). Screening depressed patients in a family practice: A rapid technique. Postgraduate Medicine, 52, 8185.

Bradburn, N. M. (1969). The structure of psychological well-being. Chicago: Aldine.

Brickman, P., \& Berman, J. J. (1971). Effects of performance expectancy and outcome uncertainty on interest in social comparison. Journal of Experimental Social Psychology. 7, 600-609.

Brickman, P., \& Bulman, R. (1977). Pleasure and pain in social comparison. In J. M. Suls \& R. L. Miller (Eds.), Social comparison processes: Theoretical and empirical perspectives (pp. 149-186). Washington DC: Hemisphere.

Butler, A. C., Hokanson, J. E., \& Flynn, H. A. (1994). A comparison of self-esteem lability and low trait self-esteem as vulnerability factors for depression. Joumal of Personality and Social Psychology, 66, 166-177.

Buunk, B. P., Collins, R. L., Taylor, W. E., VanYperen, N. W., \& Dakof, G. A. (1990). The affective consequences of social comparison: Either direction has its ups and downs. Journal of Personality and Social Psychology, 59, 1238-1249.

Campbell, A., Converse, P. E., \& Rodgers, W. L. (1976). The quality of American life. New York: Sage.

Campbell, J. D. (1990). Self-esteem and clarity of the self-concept. Journal of Personality and Social Psychology, 59, 538-549. 
Cialdini, R. B., \& Richardson, K. D. (1980). Two indirect tactics of impression management: Basking and blasting. Journal of Personality and Social Psychology, 39, 406-415.

Crocker, J., Thompson, L. L., McGraw, K. M., \& Ingerman, C. (1987). Downward comparison, prejudice, and evaluations of others: Effects of self-esteem and threat. Journal of Personality and Social Psychology, 52, 907-916.

DeVellis, R., Holt, K., Renner, B., Blalock, S., Blanchard, L., Cook, H., Klotz, M., Mikow, V., \& Harring, K. (1990). The relationship of social comparison to rheumatoid arthritis symptoms and affect. Basic and Applied Social Psychology, 11, 1-18.

Diener, E. (1994). Assessing subjective well-being: Progress and opportunities. Social Indicators Research, 31, 103-157.

Diener, E., Emmons, R. A., Larsen, R. J., \& Griffin, S. (1985). The Satisfaction With Life Scale. Journal of Personality Assessment, 49, $71-75$

Dweck, C. (1986). Motivational processes affecting learning. American Psychologist, 41, 1040-1048.

Dweck, C., \& Leggett, E. (1988). A social-cognitive approach to motivation and personality. Psychological Review, 95, 256-273.

Ekman, P., \& Davidson, R. J. (1994). The nature of emotion: Fundamental questions. Oxford: Oxford University Press.

Eysenck, H. J., \& Eysenck, S. B. G. (1975). Manual of the Eysenck Personality Questionnaire. London: Hodder \& Stoughton.

Festinger, L. (1954). A theory of social comparison processes. Human Relations, 7, 114-140.

Festinger, L. (1957), A theory of cognitive dissonance. Stanford, CA: Stanford University Press.

Fiske, S. T., \& Taylor, S. E. (1991). Social cognition (2nd ed.). New York: McGraw-Hill.

Forgas, J. P. (1995). Mood and judgment: The affect infusion model (AIM). Psychological Bulletin, 117, 39-66.

Freedman, J. (1978). Happy people: What happiness is, who has it, and why. Ncw York: Harcourt Brace Jovanovich.

Gibbons, F. X. (1986). Social comparison and depression: Company's effect on misery. Journal of Personality and Social Psychology, 5I, 140-148.

Gibbons, F. X., \& Gerrard, M. (1989). Effects of upward and downward social comparison on mood states. Journal of Social and Clinical Psychology, 8, 14-31.

Gilbert, D. T., Giesler, R. B., \& Morris, K. A. (1995). When comparisons arise. Journal of Personality and Social Psychology, 69, 227236.

Hakmiller, K. L. (1966). Threat as a determinant of downward comparison. Journal of Experimental Social Psychology (Suppl. 1), 32-39.

Heatherton, T. F., \& Polivy, J. (1991). Development and validation of a scale for measuring state self-esteem. Journal of Personality and Social Psychology, 60, 895-910.

Kernis, M. H., Cornell, D. P., Sun, C., Berry, A., \& Harlow, T. (1993). There's more to self-esteem than whether it is high or low: The importance of stability of self-esteem. Journal of Personality and Social Psychology, 65. 1190-1204.

Lyubomirsky, S. (1994). The hedonic consequences of social comparison: Implications for enduring happiness and transient mood. Unpublished doctoral dissertation, Stanford University.

Lyubomirsky, S., \& Lepper, H. (1997). A measure of subjective happiness: Preliminary reliability and construct validation. Manuscript submitted for publication, University of California, Riverside.

Lyubomirsky, S., \& Ross, L. (1990). Cognitive strategies to enhance happiness: Choosing to be happy. Working paper, Stanford University.

Lyubomirsky, S., \& Ross, L. (1997). Changes in attractiveness of elected, rejected, and precluded alternatives: A comparison of "happy" and "unhappy" individuals. Manuscript submitted for publication, Stanford University.
Major, B., Testa, M., \& Bylsma, W. H. (1991). Responses to upward and downward social comparisons: The impact of esteem-relevance and perceived control. In J. Suls \& T. A. Wills (Eds.), Social comparison: Contemporary theory and research (pp. 237-260). Hillsdale, NJ: Erlbaum.

Morse, S., \& Gergen, K. J. (1970). Social comparison, self-consistency, and the concept of self. Journal of Personality and Social Psychology, $16,148-156$.

Myers, D. G., \& Diener, E. (1995). Who is happy? Psychological Science, $6,10-19$.

Pittman, R. K., Orr, S. P., Forgue, D. F., Altman, B., deJong. J. B., \& Herz, L. R. (1990). Psychophysiological responses to combat imagery of Vietnam veterans with PTSD versus other anxiety disorders. Journal of Abnormal Psychology, 99, 49-54.

Rosenberg, M. (1965). Society and the adolescent self-image. Princeton, NJ: Princeton University Press.

Rosenthal, R., \& Rosnow, R. (1985). Contrast analysis. Cambridge, England: Cambridge University Press.

Rosnow, R., \& Rosenthal, R. (1989). Definition and interpretation of interaction effects. Psychological Bulletin, 105, 143-146.

Ross, L., Lepper, M. R., \& Hubbard, M. (1975). Perseverance in selfperception and social perception: Biased attributional processes in the debriefing paradigm. Journal of Personality and Social Psychology, 32, 880-892.

Scheier, M. F., \& Carver, C. S. (1985). Optimism, coping, and health: Assessment and implications of generalized outcome expectancies. Health Psychology, 4, 219-247.

Seidlitz, L., Wyer, R. S., \& Diener, E. (1997). Cognitive correlates of subjective well-being: The processing of valenced life events by happy and unhappy persons. Journal of Research in Personality, 3I, 240256 .

Suls, J. M. (1977). Social comparison theory and research: An overview from 1954. In J. M. Suls \& R. L. Miller (Eds.), Social comparison processes: Theoretical and empirical perspectives ( $\mathrm{pp} .1-19)$. Washington, DC: Hemisphere.

Swallow, S. R., \& Kuiper, N. A. (1988). Social comparison and negative self-evaluations: An application to depression. Clinical Psychology Review, 8, 55-76.

Swallow, S. R., \& Kuiper, N. A. (1990). Mild depression, dysfunctional cognitions, and interest in social comparison information. Journal of Social and Clinical Psychology, 9, 289-302.

Swallow, S. R., \& Kuiper, N. A. (1992). Mild depression and frequency of social comparison behavior. Journal of Social and Clinical Psy. chology, 11, 167-180.

Swann, W. B., Jr. (1983). Self-verification: Bringing social reality into harmony with the self. In J. Suls \& A. G. Greenwald (Eds.), Social prychology perspectives (Vol. 2, pp. 33-66). Hillsdale, NJ: Erlbaum.

Swann, W. B., Jr. Wenzlaff, R. M., Krull, D. S., \& Pelham, B. W. (1992). Allure of negative feedback: Self-verification strivings among depressed persons. Journal of Abnormal Psychology, 101, 293-306.

Taylor, S. E., Aspinwall, L. G., Giuliano, T. A., Dakof, G. A., \& Reardon, K. (1993). Storytelling and coping with stressful events. Journal of Applied Social Psychology, 23, 703-733.

Taylor, S. E., \& Lobel, M. (1989). Social comparison activity under threat: Downward evaluation and upward contacts. Psychological Review, 96, 569-575.

Taylor, S. E., Wood, J. V., \& Lichtman, R. R. (1983). It could be worse: Selective evaluation as a response to victimization. Joumal of Social Issues, 39, 19-40.

Tellegen, A. (1985). Structures of mood and personality and their relevance to assessing anxiety, with an emphasis on self-report. In A. H. Tuma \& J. D. Maser (Eds.), Anxiety and the anxiety disorders (pp. 681-706). Hillsdale, NJ: Erlbaum.

Tesser, A. (1988). Toward a self-evaluation maintenance model of social 
behavior. In L. Berkowitz (Ed.), Advances in experimental social psychology (Vol. 21, pp. 181-222). New York: Academic Press.

Tesser, A., Millar, M., \& Moore, J. (1988). Some affective consequences of social comparison and reflection processes: The pain and pleasure of being close. Journal of Personality and Social Psychology, 54, $49-61$.

Watson, D., Clark, L. A., \& Tellegen, A. (1988). Development and validation of brief measures of positive and negative affect: The PANAS scales. Journal of Personality and Social Psychology, 54, 10631070.

Wayment, H., \& Taylor, S. E. (1995). Self-evaluation processes: Motives, information use, and self-esteem. Journal of Personality, 63, 729-757.

Weary, G., Elbin, S., \& Hill, M. G. (1987). Attributional and social comparison processes in depression. Journal of Personality and Social Psychology, 52, 605-610.

Wegner, D. M., \& Pennebaker, J. W. (1993). Handbook of mental control. Englewood Cliffs, NJ: Prentice Hall.

Wenzlaff, R. M., Wegner, D. M., \& Klein, S. B. (1991). The role of thought suppression in the bonding of thought and mood. Journal of Personality and Social Psychology, 60, 500-508.
Wheeler, L. (1966). Motivation as a determinant of upward comparison. Journal of Experimental Social Psychology (Suppl. 1), 27-31.

Wheeler, L., \& Miyake, K. (1992). Social comparison in everyday life. Journal of Personality and Social Psychology, 62, 760-773.

Wills, T. A. (1981). Downward comparison principles in social psychology. Psychological Bulletin, 90, 245-271.

Wills, T. A. (1991). Similarity and self-esteem in downward comparison. In J. Suls \& T. A. Wills (Eds.), Social comparison: Contemporary theory and research (pp. 51-78). Hillsdale, NJ: Erlbaum.

Wood, J. V., Taylor, S. E., \& Lichtman, R. R. ( 1985). Social comparison in adjustment to breast cancer. Journal of Personality and Social Psychology, 49, 1169-1183.

Wood, J. V., Giordano-Beech, M., Taylor, S. E., Michela, J. L., \& Gaus, V. (1994). Strategies of social comparison among people with low self-esteem: Self-protection and self-enhancement. Journal of Personality and Social Psychology. 67, 713-731.

Received January 24, 1996 Revision received December 13, 1996 Accepted January 21, 1997 